\title{
Collaborative place-based health governance systems: stakeholders' perceptions in the Portuguese Baixo Vouga sub-region
}

\author{
Governança colaborativa de base local em sistemas de saúde: \\ percepções dos stakeholders na sub-região do Baixo Vouga português
}

Carlos Gonçalves (https://orcid.org/0000-0002-8571-1287) ${ }^{1}$

Gonçalo Santinha (https://orcid.org/0000-0002-4732-5959) ${ }^{1}$

Anabela Santiago (https://orcid.org/0000-0002-3897-0323) ${ }^{1}$

Gonçalo Barros (https://orcid.org/0000-0001-9563-3318) ${ }^{1}$

${ }^{1}$ Departamento de Ciências Sociais, Políticas e do Território, Unidade de Investigação em Governança,

Competitividade e Políticas Públicas (GOVCOPP), Universidade de Aveiro. Campus Universitário de Santiago. 3810-193

Aveiro Portugal.

carlosgoncalves@ua.pt
Abstract This study aimed to assess the Baixo Vouga sub-region (Portugal) governance system through 15 interviews with leaders of institutions with decision-making power and provide healthcare. The interviews were subjected to a content analysis, organized in matrices by cases, categories, subcategories, and indicators. Recording units were extracted from the interviews to produce data for each indicator. A Collaborative Place-based Governance Framework systematizing operational definitions of collaborative governance was implemented to serve as a benchmark for assessing the collaborative and place-based dimensions. The Baixo Vouga sub-Region governance system is collaborative because it is based on a shared structure of principles that translates into the services provided. It has a multilevel and multisector collaboration, and can undertake shared decisions. These dimensions could be reinforced through increased participation, autonomy, subsidiarity if more place-based information and practical knowledge were sought. The system would also benefit from an extensive adoption of bottom-up methods to formulate and implement policies.

Key words Collaborative place-based governance, Health governance, Communities health gains, Participation, Accessibility
Resumo Esta investigação tem como objetivo avaliar estas dimensões no sistema de governança da Região de Aveiro (RA) Portugal, através de 15 entrevistas feitas aos responsáveis máximos de instituições que decidem e que prestam cuidados. $\mathrm{Na}$ análise das entrevistas, aplicaram-se me-todologias de análise de conteúdo. Para o efeito, criaramse matrizes por casos, sub-categorias, sucategorias e indicadores. Das gravações das entrevistas, extrairam-se unidades de registo para cada indicador. Propomos um referencial de governança colaborativa de base local que sistematiza definições operativas de governança colaborativa, servindo, depois, de referencial para o exercício de avaliação. O sistema de governança da sub-região do Baixo Vouga é colaborativo porque assenta numa estrutura partilhada de princípios transposta para o modo como os serviços são prestados. Apresenta colaboração multinível e multissetorial e capacidade de construir decisões partilhadas. Reforçarse-iam estas dimensões com mais participação, autonomia, subsidiariedade e se se recorresse mais à informação e a conhe-cimento prático, localizado. Também beneficiaria com a adoção extensiva de metodologias de base local na formulação e na implementação de políticas.

Palavras-chave Governança colaborativa de base local, Governança em saúde, Ganhos em saúde, Participação, Acessibilidade 


\section{Introduction}

Collaborative governance is an arrangement where state agencies directly recruit stakeholders in a collective, formal, consensus-oriented, deliberative decision-making process and aims to establish or implement state policies ${ }^{1}$. It is essential to make a clear distinction between the three stages or processes of this governance arrangement: (i) principles, (ii) processes, and (iii) outcomes.

We should focus on structures and rules (both formal and informal) governing the supply-demand relationship when questioning the health systems' building block approach. This means understanding these rules and how individuals, groups, and governments shape, change, monitor, and enforce rules and the corresponding outcomes and consequences. The need for collaborative governance is even more relevant in decentralization processes concerning criteria for policymakers or communities ${ }^{2}$. Decentralization has advantages and multiple challenges - keeping enough multilevel coherence and equity, cost-effectiveness, and coordination within a governance system, which considers issues such as bringing healthcare closer to the local populations' needs (place-based health systems), stronger community ownership, more opportunities for tailoring and bottom-up approaches, and faster and more flexible collaborative decision-making.

Place-based health systems are a promising strategy for improving community healthcare ${ }^{3}$. In these programs, local authorities and other players collaborate to employ health-promoting interventions and policies ${ }^{1}$. Two factors drive locally-directed place-based healthcare services. The first is the general appeal of decentralization, i.e., the transfer of financial resources and autonomy to a lower level of governance. The second concerns the issue of accountability of such integrated place-based healthcare services, linked to its base of evidence.

In the context of Portuguese healthcare systems, a reform (mainly in primary healthcare) was initiated in 2005, creating a new institutional landscape based on bottom-up principles, transference of autonomy and responsibilities to pursue quality and accessibility improvements. The main instrument used was contractualization, i.e., the development and implementation of formal agreements where one party (funding) provides compensation to the other party (provider) in exchange for a set of healthcare services directed to a specific group of population ${ }^{4}$.
The research questions driving and informing this study are the following: How do stakeholders perceive the Baixo Vouga Health System governance? Considering the stakeholders' perceptions, is the Baixo Vouga sub-region Health System governance collaborative and placebased? If so, in what way? If not, why and what is needed to (re)develop the 'missing links'?

This paper follows a research-based case study with qualitative information extracted from 15 face-to-face semi-structured interviews carried out from January to June 2019. The interviews show the stakeholders' internal perceptions of the leadership in the Baixo Vouga sub-Regional health system (sRBV). The results were set against the principles summarized in the collaborative, place-based governance health system framework.

\section{Conceptual Framework}

This section discusses the importance of collaborative governance in implementing healthcare policies. It presents definitions and proposes a scalable Collaborative Health System Governance Framework (principles, processes, outcomes). Then, it summarizes the attributes associated with the collaborative place-based governance in the Portuguese healthcare system structure.

\section{Collaborative Governance in Place-based Healthcare Policies}

Formulating policies with the presumption of rolling them out at the local level is an appropriate way of fighting inequalities. In many contexts, non-governmental organizations are pioneers in rolling out local healthcare programs alongside other bodies such as councils, thus exemplifying close community collaboration efforts. Evidence suggests that individual players manage to successfully carry out individual actions alongside communities, particularly in primary healthcare provision ${ }^{5}$. This type of collaboration is sustainable in several levels and may be extended to healthcare policy assessment and development stages $^{3}$. Still, regardless of stage, the capacity to include the collaborative phase (which increases implementation capacity) in the design of governance systems depends on political, social, economic, cultural, and historical factors. Lowe et al. ${ }^{6}$ identify four policymaking elements that should be considered for these purposes: players, context, processes, and content. 
Regarding practical strategies to address primary health care, Abimbola et al..$^{5}$ put forward a multilevel framework where interactions are defined as: i) operational governance (providers) in the process by which individual local healthcare system players make decisions on the supply and demand of services in their community; ii) collective governance (communities), action by community or representatives who bring them into partnership with their providers; and iii) constitutional governance, actions, and decisions of governments and similar bodies in setting, dictating, and influencing the rules governing collective and operational actions and decisions ${ }^{5}$.

Strengthening governance systems is a way of acting on healthcare determinants, which depend on other sectors' behavior out of their reach, including but not limited to social security, city planning, and transport. It involves local players and residents in identifying problems and seeking solutions. Thus, "place-based programs" fit a collaborative governance model ${ }^{2}$. Operationalization of assisted business techniques is at stake, and conditions are created for stakeholders to participate directly. Institutions responsible for policies assume the role of facilitators, focusing on maintaining the capacity to manage consensus. To this end, it is essential to highlight the leadership's role, i.e., responsibility for maintaining transparency in rules, building confidence, enabling dialogue, and exploring potential winwin situations?

Three components of collaborative leadership suited to mobilizing the creation of collaborative policies are identified. They should be suitable for managing collaborative procedures, inspire technical credibility, and promote empowerment, thus guaranteeing the necessary level of credibility for decisions taken to be accepted by $\mathrm{all}^{8}$. Well-implemented governance structures should be set in a shared leadership network rather than relying on a single leader ${ }^{7}$. Movement in the architecture of health governance systems requires decentralized structures, where disperse and heterogeneous networks of players representing multiple sectorial interests can manage shifts in consensuses for policy instruments, thus improving the population's health quality of life in coordinated fashion ${ }^{2}$.

\section{Collaborative Governance: Operational Definitions}

The application of collaborative governance systems to healthcare provision is recent and lacks suitable methods to assess its quality. Thus, it is necessary to look at examples available that draw attention to those who may be applied to the governance of healthcare systems, cross-sectionally (multilevel and multisectoral) conceiving its operationalization. A comprehensive quality assessment of governance systems allows technicians and politicians to rank solutions for identified problems and replicate best practices tested on different interventionist scales. These methods should comply with a set of requirements, namely, good governance and political commitment, effective bureaucratic and institutional policy, the ability to innovate, especially concerning service delivery, and healthcare system resilience?.

Definitions of governance applied to healthcare systems allow extracting cross-sectional operational dimensions to compile a reference point that could be applied to empirical analysis exercises, which might produce practical advice and solutions $s^{2,10}$. Thus, governance systems quality may be verified, and the level of stakeholder involvement is translated into action across sectors as a multi-scaled interaction, whether or not these interactions manage visibly shared meanings to learn to incorporate change.

Consistency in collaborative governance systems translates into the intensity level of consensus achieved between formal/informal rules to adjust demand and supply involving state/private stakeholders in decisions/actions, which benefit these informal arrangements. The balance which accrues from the contribution of these different dimensions in collaborative healthcare governance systems is transposed into place-based results, which are prepared for curbing inequalities and are more inclusive across the collective and transformative process (Chart 1).

Frameworks that evaluate the quality of health governance systems have manifold objectives, not just on occasion, which is far from being clear and even, and can also be conflicting in nature. Pyone et al. ${ }^{11}$ put forward an overview of various review methods' qualities, considering multiple analytical focal points, targets, and potential applications. This draft may be rounded off with a survey of the different tools used to appraise the functionality of governmental systems put forward by Baez-Camargo \& Jacobs ${ }^{10}$.

Under the specific territorial context, collaborative governance systems emphasize firm fundamental values such as "control of corruption", "ethics and integrity" or "conflict prevention". These are always linked to the objectives of facil- 
itating the implementation of plans and strategic actions, unleashing democratic mechanisms, and defending human rights ${ }^{5}$. A central aspect of the intensity of governmental systems resides in the set of formal (elections, appointments, and parliaments) and informal (trust, reciprocity, collective mindset, and supplier/end-user relationships) rules agreed upon for the distribution of authority, functions, and responsibilities between social players, thus repositioning trade-offs based on primary and chief agents ${ }^{12}$.

A collaborative place-based governance system shares a structure of principles and processes that allow achieving outcomes such as accountability, reduced health inequalities, cross-sector collective actions, and health improvements (Figure 1).

\section{Collaborative place-based Governance in Portuguese Primary Health Care Systems}

The First International Conference organized in 1978 by the World Health Organization (WHO) on Primary Health Care in Alma-Ata, Kazakhstan (former Soviet Union) proposed to achieve a "Health for All by 2000" goal through the implementation and development of "Primary Health Care" worldwide. The creation of place-based health systems was assumed to be the most effective way to implement the subsidiarity principle. Primary health care should be the first level of contact of individuals, family, and community with the national health system, drawing health care as close as possible to where people live and work, and was the first element of a continuing healthcare development process ${ }^{14}$.

The design of local healthcare systems, integrated with the regional and national levels,

Chart 1. Collaborative Governance Operational Dimensions.

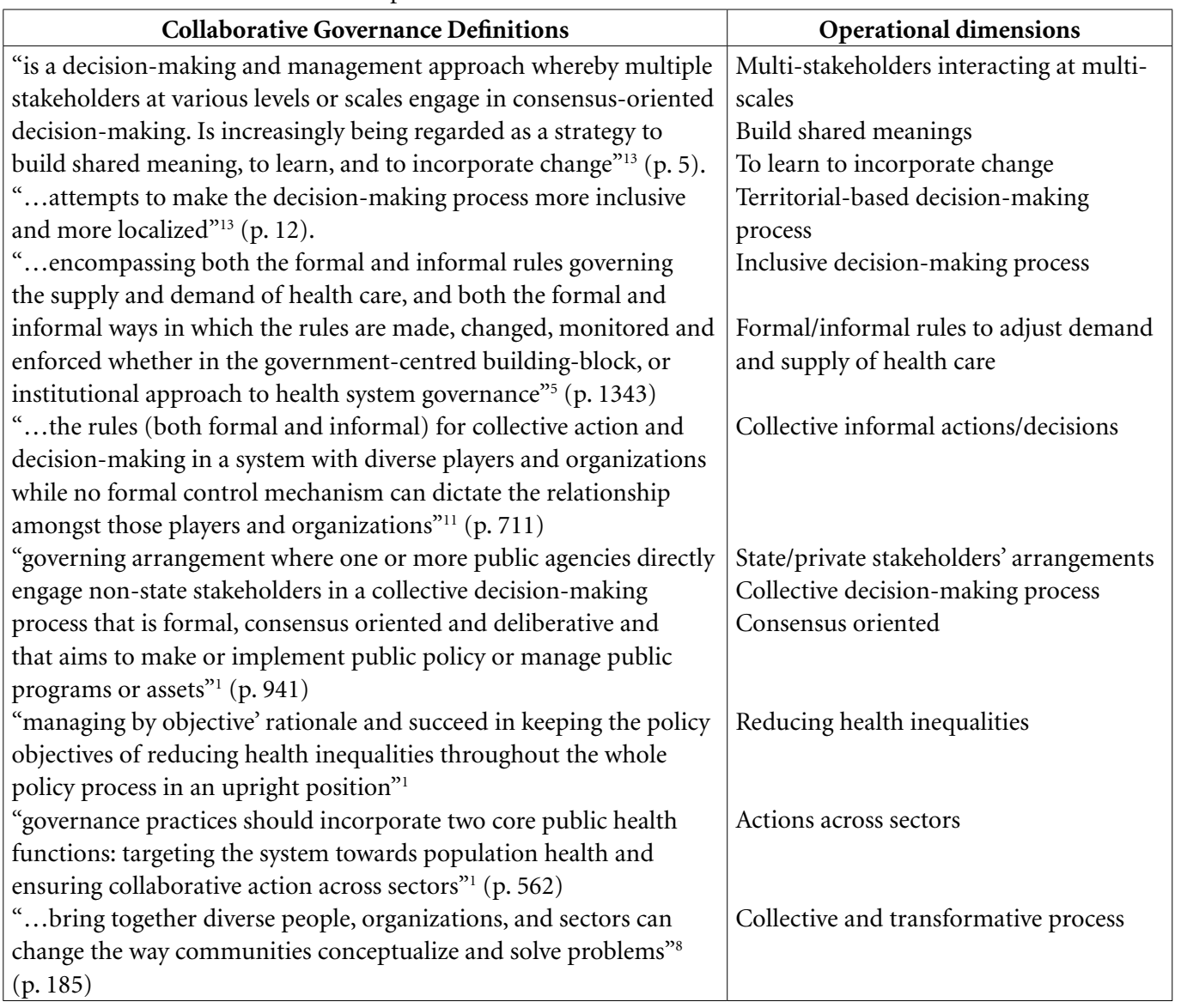

Source: Own elaboration based on the cited authors. 


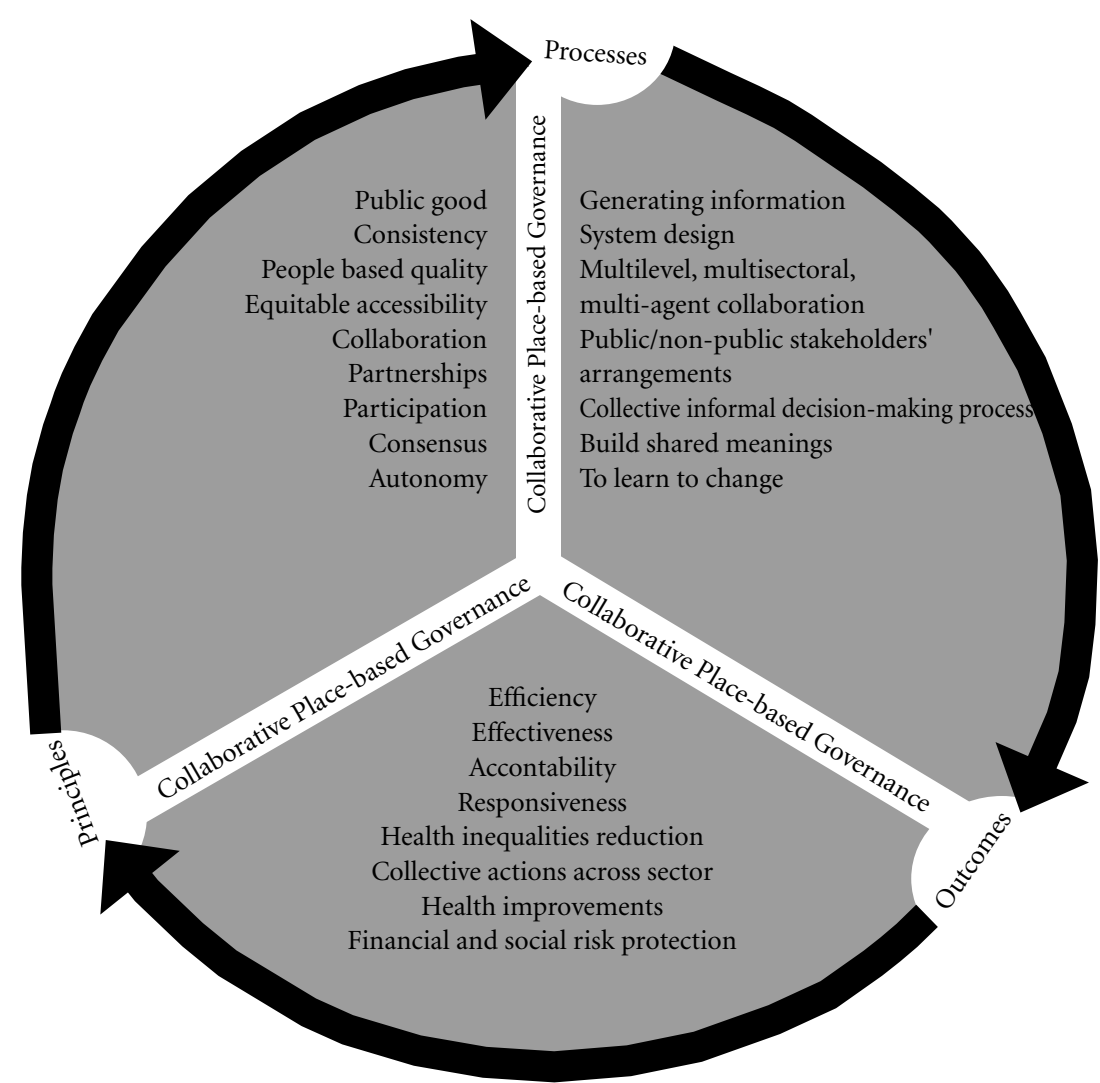

Figure 1. Collaborative Place-based Governance Framework: principles, processes, outcomes.

Source: Own elaboration.

brings together multidisciplinary efforts made by health professionals and associations, organized by state participation mechanisms that bring the provision of care closer to the needs of the communities. In Portugal, a Place-based Collaborative Governance was created in 1971, under Decree-Law No. 413/71, carrying out the first reform of the Ministry of Health services (in 1958) and creating the "first-generation health centers"14. This initiative was followed by others, consolidating the local component of the Portuguese healthcare system through territory-based responses (Figure 2).

The institutions and contracting mechanisms to foster teams' initiatives to create locally-based health responses were developed through incentives. The monitoring of contracts was established through indicators increasingly adjusted to the challenges of promoting healthcare instead of addressing the disease (Figure 2).
The Portuguese Health System (Figure 3) derives from the coexistence of three sub-systems, namely, the National Health System, the State and Private Health Systems for specific groups (for example, civil servants), and the Private Sub-system. In recent years, the cooperation initiatives between entities, led by municipalities, have increased, aiming mostly at reducing traffic accidents, and promoting pedestrians' safety, physical activity, and healthy eating habits. However, the representativeness of these initiatives is still limited ${ }^{15}$.

However, contracting mechanisms within the health system have become a practice applied extensively by teams (made up of autonomous proposals) in various types of Local Health Units (USFP, UCC, UCSP, USF). Several binding agreements (depending on results, levels of efficiency, transparency, and equity) have been entered into with regional and sub-regional institutions (be- 
$1^{\text {st } W H O ~ C o n f e r e n c e ~ " H e a l t h ~ f o r ~ A l l ~ b y ~ 2000 " ~}$ Goal: global PHC implementation

Medical career in General Practice Goal: health care to meet familie needs

$1^{\text {st }}$ contractualization experience at ARSLVT Goal: to improve equity and access to health

New remuneration modality for doctors Goal: salary linked to the quantity and quantity of performance

Mission for $\mathrm{PHC}$ Goal: implementing PHC reform

49 indicators (access, assistance performance, perceived quality, economic performance) Goals: contractualization implementation and monitorization

Annual program contracts based in sociodemographic, socioeconomic and health outcomes indicators
Decree Law No. 413/71

Goal: Primary Portuguese Health Care

(PHC): Local Health Centers (LHC)

1978

Regional Health Administrations Goal: $2^{\text {nd }}$ generation LHC

1983

Alpha Project (organizational experience) Goal: link autonomy and responsibility

1996

Health Services Contractualization Agencies Goal: "agency" among citizens and health care services

Health Services Monitoring Agency.Goal: performance evaluation of LHC; contractualization of PHC

2005

$1^{\text {st }}$ Family Health Units.Goals: involvement of health professionais, voluntary application, bottom up process

$2006 / 7$

USF model B

Goals: salary incentives for teams for performance

Personalized Health Care Units; Community Health Units; Public Health Units

Figure 2. Main events that organized the local component of the Portuguese health system.

Source: Own elaboration.

tween the 5 ARSs and the 482 Local Health Center Associations (ACES), and between the ACES and the 1,278 Family Health Units (USF)). These agreements secure financing to pursue goals (access, assistance performance, perceived quality, and economic performance) for specific sets of indicators corresponding to health care provision to set communities (Figure 3).

The monitoring and review of agreements are transparent, allowing any citizen to read and monitor them (through platforms such as Dashboard - Primary Health Care Identity Card), besides the characteristics of the communities, the trend (daily, in some cases) of the results achieved by the USF teams, which enables assessing the behavior of indicators to the level of ARS, ACES, and each USF, including tools of compared visu- alization regarding access (7 indicators), illness management ( 8 indicators), healthcare management (4 indicators), and patients' satisfaction (1 indicator).

\section{Case-study localization and methods}

The ARS of Centro Region is subdivided into 9 ACES. In 2016, $17 \%$ of the population of mainland Portugal lived in this region $(1,674,660$ inhabitants). According to this ARS Activity Plan for 2019, in the previous month of December, the Region had 1,782,088 registered users, 1,465 doctors, 1,393 nurses, and 5,951,129 realized appointments ${ }^{16}$.

The fieldwork was performed through 15 semi-structured interviews with leaders (coordi- 


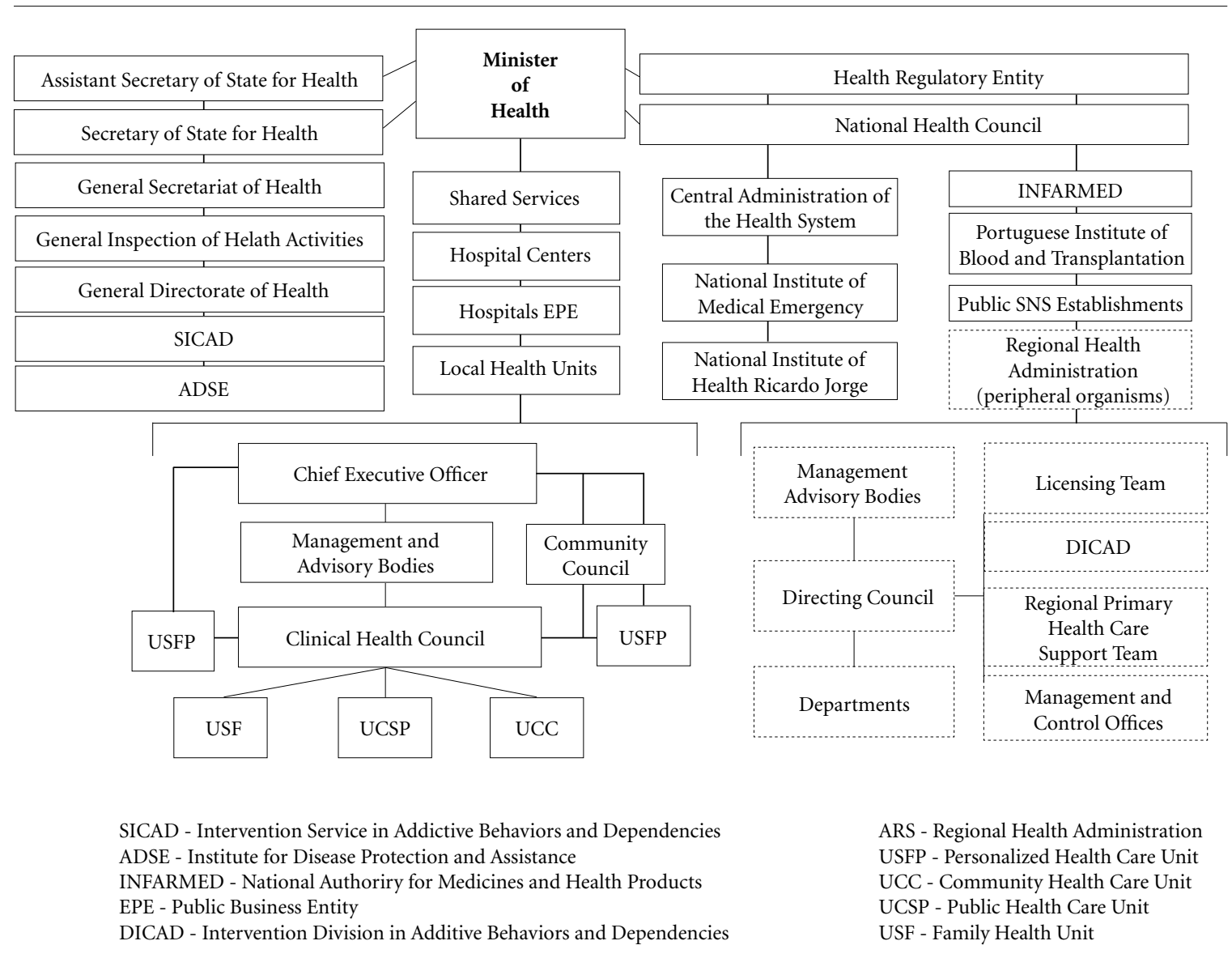

Figure 3. National, regional, and sub-regional health governance system.

Source: Own elaboration.

nators, presidents of boards, and directors) of institutions in the healthcare network governance system of this region. One of its nine sub-regions was selected as a case study: Baixo Vouga (sRBV), corresponding to the scope of ACES with that designation (Figure 4). The selected respondents were top officials responsible for coordinating regional policies (CCDR-Centro), coordinating inter-municipal policies (CIRA), the regional implementation of health policies (ARS), hospital care management (BV Hospital Center), supervision of primary care in the RA (ACES), and providing primary healthcare (6 USFs, 3 UCCs, 1 USP, and 1 UCCi).

In October 2019, this sub-region had 52 primary healthcare units, 393,970 registered users, 262 doctors, and 318 nurses (sns.gov.pt/). The sRBV exemplifies this type of health governance system's workings, revealing the principles and intensity of the structuring articulation. The RA has a non-metropolitan health governance system, combining densely populated areas with dispersed urbanization areas and other rural areas of low and declining density.

Our analysis was based on the recorded audio files of the 15 face-to-face interviews with the leaders of the institutions listed in the caption of Figure 4. A total of 12 hours and 35 minutes of content was collected, ranging from 20 minutes (the shortest interview) to 70 minutes (the longest one).

The contents of each interview (each case) were organized by reference into three categories (principles, policies, and governance), which in turn were broken down into subcategories: i) policymaking principles and their multi-scale 
a)

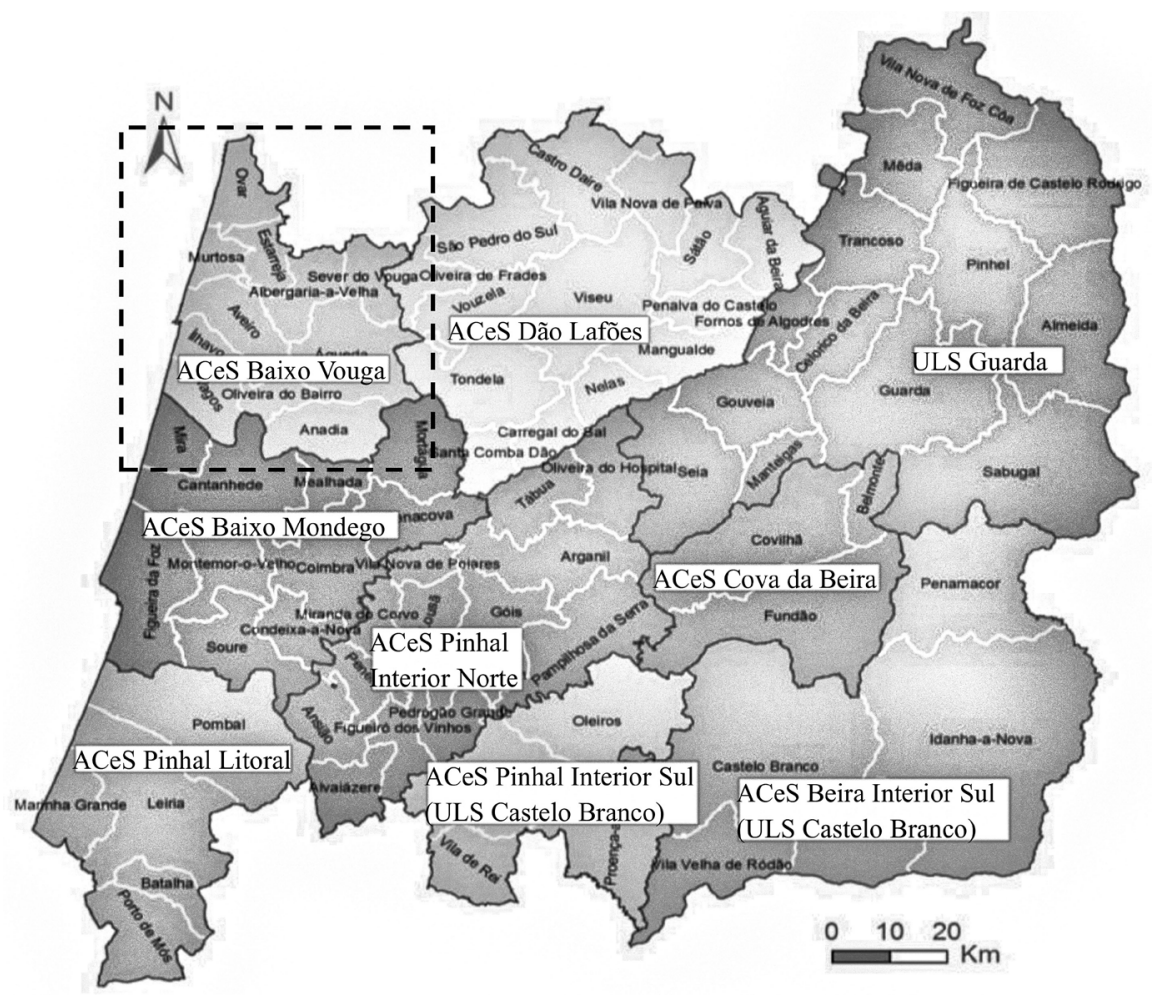

b)

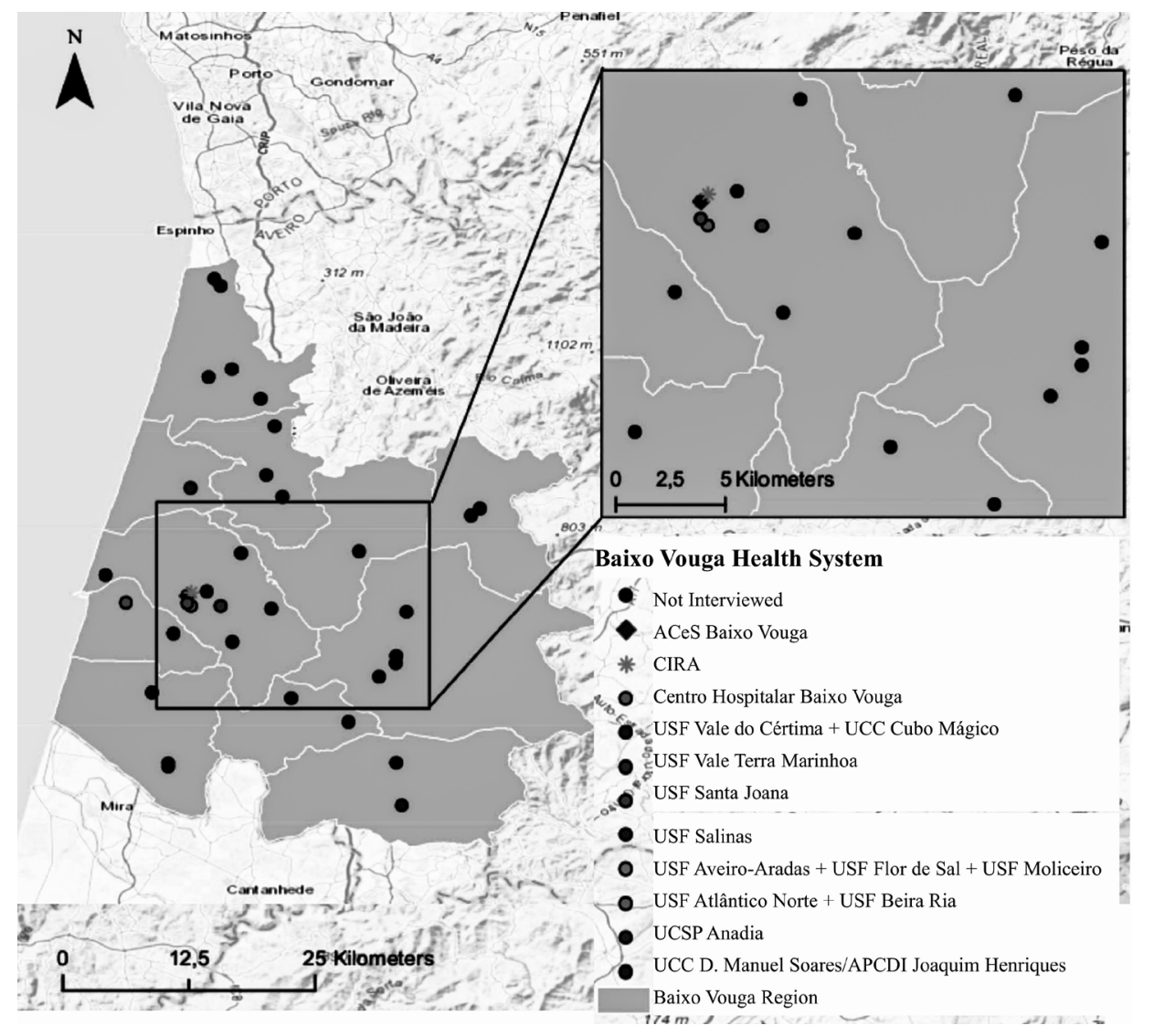

Figure 4. Framework of the study area and location of the interviewed entities. 
and coherence with practice; ii) policymaking, participation and implementation practices; and, iii) policymaking and vertical/horizontal collaboration. A matrix was organized with the information for 33 registration units. The systematization of the results obtained for the referred subcategories is shown below.

\section{Results}

This section presents the results of the interviews. It reviews: i) the principles that guide the formulation of healthcare policies; ii) its multilevel and multisectoral integration; ii) consistency between the principles and practices of healthcare; the modus operandi adopted in the formulation of policies; iv) how they integrate stakeholder's participation; and, v) the levels of vertical (across scales) and horizontal (across sectors) collaboration. The principles, processes, and outcomes are observed from the stakeholders' inner perceptions in RA, in dialogue with the Collaborative Place-based Health Governance Systems framework (Figure 1). The tables where the results are shown point out to the interviews, considering the hierarchy of the Regional System (RS), Baixo Vouga Subsystem (BVsS), and Community Network (CNtw).

\section{Policymaking principles and its collaborative multi-scale exercise}

Stakeholders argue that the most relevant principles for policy formulation are accessibility (proximity and affordability), equity (more for those who need it most), respect for the patient (the patient is not a disease, he is a full-fledged human being), quality (everyone benefits from what is best), efficiency (quality at the lowest possible cost), innovation (gradual improvements) and preventive action (preventing people from getting sick instead of treating diseases). The second group of principles that policies must pursue relates particularly to good management: balanced distribution of resources, health gains, and qualification of human resources (Table 1).

There are no divergences on the principles that should guide policies between the entities coordinating services at regional and sub-regional levels (from 1 to 3 and 5) and those providing them. However, specific aspects related to accessibility, participation, efficient resource management, or the importance of governance are mentioned. According to the respondents, these principles would be better implemented with more investment, leaders capable of mobilizing transformations, greater horizontal integration of decision processes, and effective subsidiarity.

Taken as a whole, sRBV's governance system shows common perceptions about the principles that healthcare provision policies should achieve. That is, equity in access to care, quality of services, proximity, adoption of forms of participatory management that produce gains in health (Table 1). The sRBV's stakeholders advocate policies linked to the principles of good management. This assumes participation, qualified human resources, innovation, cost-effectiveness, and equitable distribution of resources. These criteria should facilitate care provision, improve access (at the lowest cost and proximity possible), and enhance equity. They must also guarantee the patients' dignity through proximity, responding to their needs, and creating security. All policies must lead to health gains, qualifying the care provided, and preventive actions.

The difficulties identified in implementing the shared framework of principles result from blockages in both subsidiarity and accessibility mechanisms. These constraints make it challenging to implement preventive policies (prevent people from getting sick) instead of personalized, responsive ones (curing sick people) and, even more, instead of depersonalized responsive policies (curing diseases). The interviewed leaders argue that these blockages would be overcome with more investment, more education in healthcare, more articulated efforts, and more efficient distribution of resources. Policies based on reliable local information would be required.

However, no incompatibilities have been identified between the principles upheld to guide the policies and how healthcare is provided. It would be necessary to improve the collaborative governance model that would facilitate involvement, integration, and coordination in order to provide care (at different scales) more coherently regarding the advocated principles (Chart 1).

It is necessary to mobilize more resources, improve their distribution and increase the accessibility and specificity of care to enable health governance systems in sRBV to realize the model idealized by this group of stakeholders. It also requires more qualification and involvement of health teams and more effective ways to generalize multidisciplinary approaches. Finally, it would be necessary to refine the contractualization and autonomy mechanisms further and increase health literacy within communities. Thus, 
Table 1. Policy guiding principles and alignment intensity of national care with those principles.

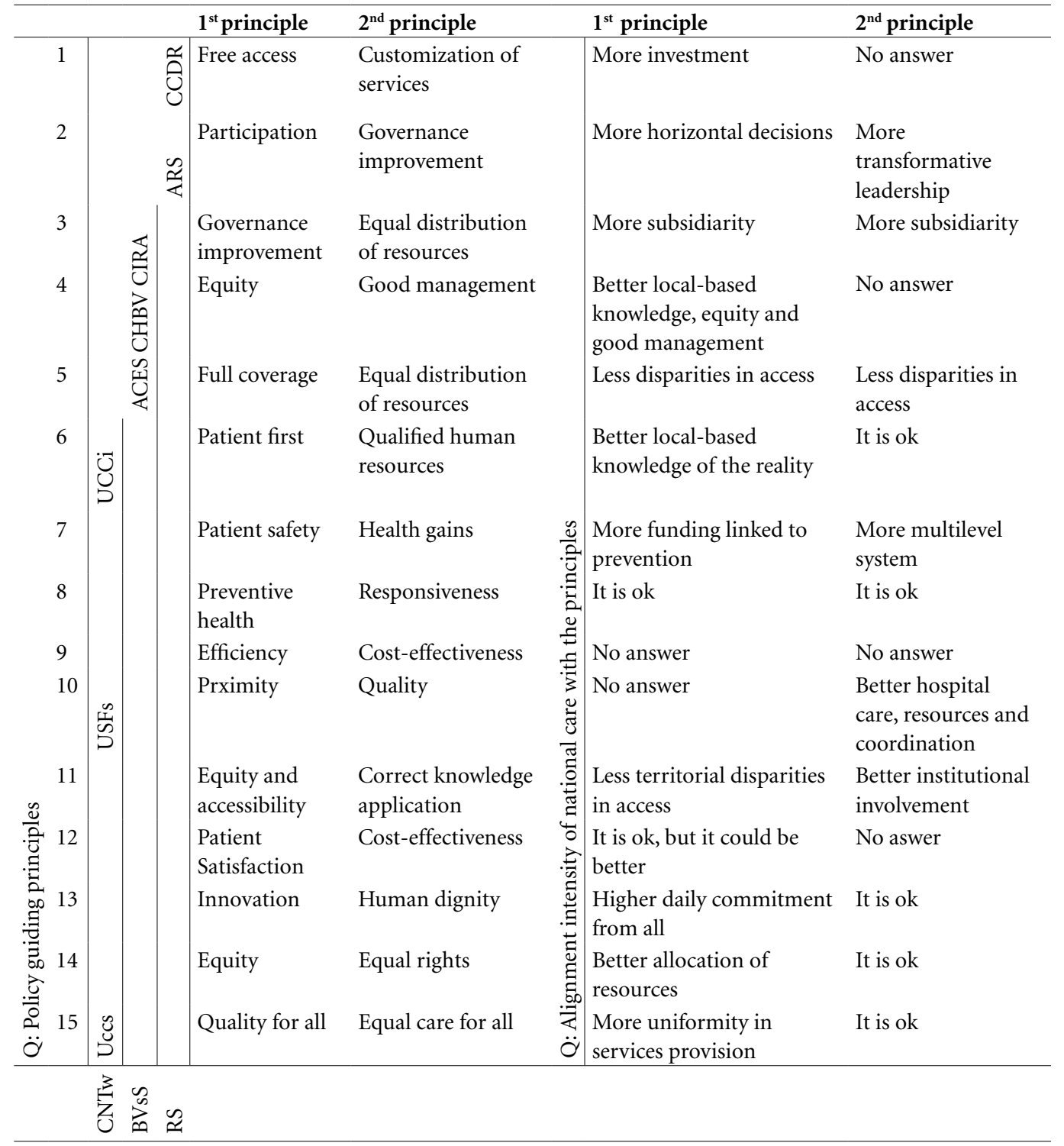

Source: Own elaboration.

the multilevel and multisectoral dimensions indispensable in a collaborative governance system would be strengthened (Figure 5).

\section{Policymaking, participation, and implementation practices}

Stakeholders' positively assessed the integration of expert opinion in policy preparation (Table 2). The informed perception regarding the use of methods, such as cost-benefit analysis, is negative. Only three of the 15 respondents positively rate this practice, and only one respondent considers it to be strong.
It is a sector with a high density of planning instruments using and creating structured information (statistics, methods, cataloging criteria, performance, and registration protocols). Therefore, according to the respondents' informed perception, the preparation of policies is based on structured information. However, if we consider the opinions of the leaders of the 11 entities providing healthcare, it appears that only two of them refer that formulating policies with structured information is positive, and 5 of the 11 state that this practice is not in place (Table 2).

In most cases, the governance system includes groups of experts responsible for proposing solu- 
tions to specific problems. The results achieved by these working groups are shown as recommendations to be included in the design of policies. It is also common for workgroups to be organized to implement pilot policy experiments, which are then implemented globally. This method explores interaction between governance bodies (from the sector and nearby sectors) and all other actors representing concrete governance system segments (professional bodies and councils, unions, associations of medical specialties, nurses, and different types of care units).

This informed perception is reflected in assessing how the different entities of the governance system participate in the policymaking process. Half of the respondents said that the actors' participation is strong, and they are joined by three more who affirm that not being strong is positive. However, there is a disagreement in assessing this practice since seven of the 15 respondents reported that this type of participation is null. That is, no participation whatsoever.

Consequently, the number of leaders who consider that their institution's participation in policy formulation is active is equal to those who evaluate it as passive. Stakeholders with active participation belong to governance institutions where policy design is decided. Thus, they inte- grate working groups formed to improve professionals' skills, solve concrete problems, or prepare policies. On the other hand, some see their participation as passive as they are only consulted when there are already consolidated proposals. The institutions least involved in the participation process state that they are only asked to follow instructions.

The integration of citizen participation in policymaking is the most negatively rated aspect. The respondents' assessment is unanimous and tells us that this is a non-existent practice. However, in most cases, it is not advocated that citizens should participate. The arguments that justify this position are the low level of literacy concerning healthcare, the inability of citizens to perceive the value of healthcare beyond immediate and individual interests (because in many circumstances it assumes real, immediate, and personal importance), and the inherent complexity of this kind of decisions.

All of the mentioned aspects converge in the way the policies are implemented. Thus, once again, we have two contrasting conclusions: i) most of the respondents (two-thirds of them) perceive their participation (when they have to internalize the guidelines in their institution) as part of a top-down, bureaucratic, hierarchical,

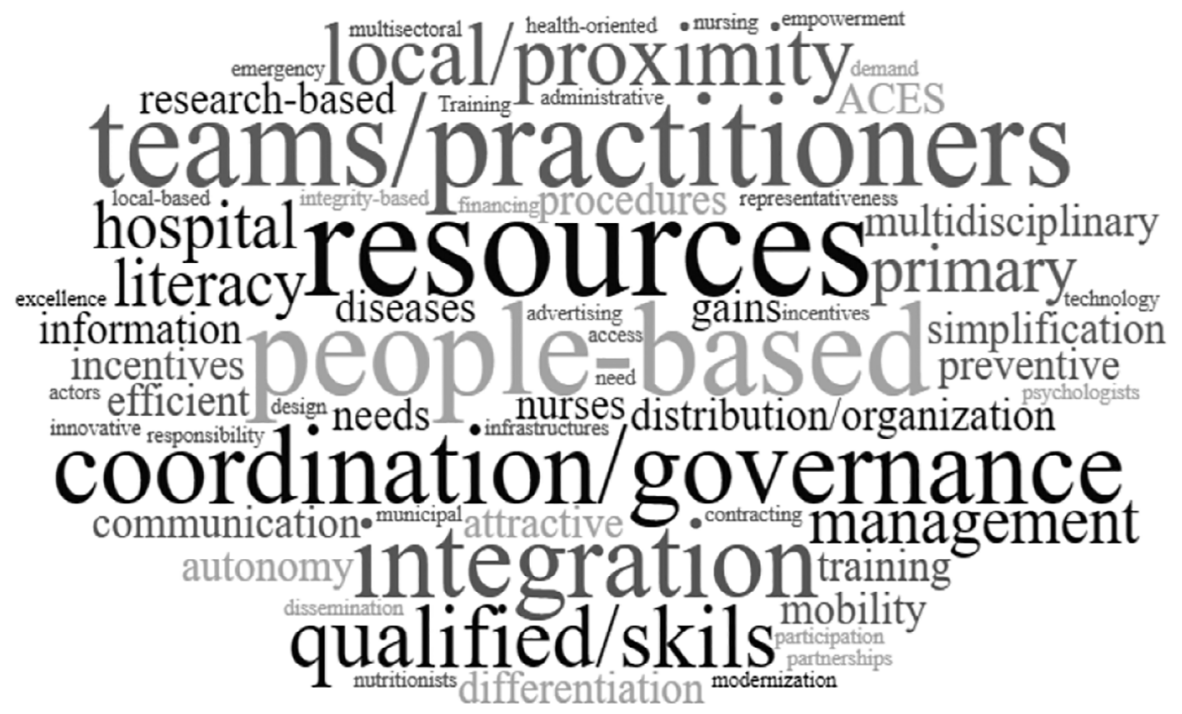

Figure 5. Dominant expressions about policies, practices, and actions required to improve the governance system. 
Table 2. Policymaking, participation, and implementation practices.

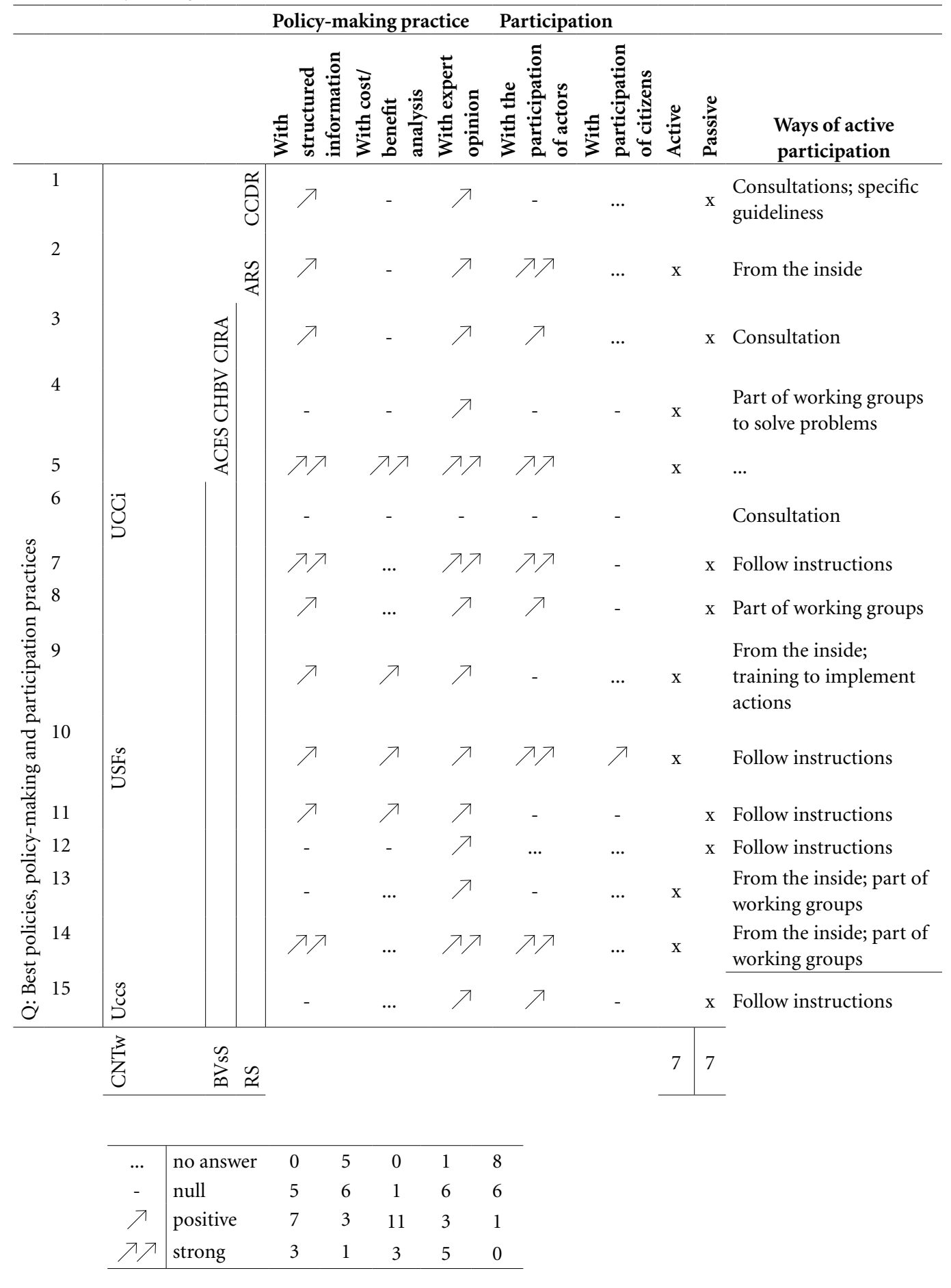

Source: Own elaboration.

and centralized structure; ii) the minority (onethird of the respondents) considers that it is part of a cooperative system, with a flexible hierarchy and the capacity to adapt to the tensions gener- ated in political decision-making centers. Some respondents take a critical stance regarding the first, while others recognize operational advantages over the second. Regarding the second, they 
point out the need to increase autonomy and devote more attention to the governance system components that are closer to the communities.

\section{Policymaking, vertical, and horizontal collaboration}

The assessment of levels of collaboration in the sRBV governance system is positive overall. Most of the respondents (two-thirds) rated collaboration between entities that make national, regional, and local decisions as positive or strong, and almost $75 \%$ of stakeholders considered collaboration between entities that implement policies as positive or strong. Moreover, two-thirds argue that collaboration with other sectors is positive or strong (Table 3 ).

The most dissenting assessments are those related to multilevel (between decision-makers of various scales) and multisectoral (between the health sector and other sectors) collaboration, where five of the 15 stakeholders say that there is no collaboration. In this segment of the evaluation, the influence of two entities in the group of those with the mission of coordinating policies at regional and intercity levels is noted. Both reject the existence of collaborative governance. The group of stakeholders providing care at the regional and local levels identifies positive or strong multilevel and intersectoral collaboration processes. The work of Community Care Units contributes to the latter type, as they design a network of partnerships to implement projects with parish councils, nursing homes, and especially in close collaboration with schools.

What would reinforce these collaboration processes? The answers point to the centrality of integration/coordination/organization between hospital care and ACES, between projects, within the scope of public health units, in the management of information systems, in the relationship with the satellite institutions of the health system, and different types of demand for care. Similarly, collaborative governance processes would benefit from the creation and enhancement of information and practical and locally-based knowledge, more decentralization of decision-making centers, the municipalization of segments of care networks, and more regional and local autonomy. Finally, they lack human (qualified) and financial resources (Table 3).

\section{Discussion and Conclusions}

This section discusses the conclusions that help answer the research questions: How do stakeholders perceive the Baixo Vouga Health System governance? Moreover, considering the stakeholders' internal perceptions, is the sub-regional Baixo Vouga Health Systems governance collaborative place-based? If so, how (2.1)? If not, why and what is needed to (re)develop the 'missing links'?

Principles such as accessibility, equity, respect for the patient, quality, efficiency (cost-effectiveness), innovation and prevention, are part of shared values space among the institutions that integrate the sRBV's governance system. This rational aggregator is complemented by types of balanced management of financial and human resources allowing for gradual health gains.

A multilevel collaboration (regional/sub-regional) has been identified, which can be improved with more investment, health literacy, more qualified leaders, greater horizontal integration (between sectors), and greater subsidiarity and accessibility. The respondents' perception points to a coincidence between the principles upheld and how care is provided and (missing links) some shortcomings (difficulties in strengthening involvement, interdisciplinarity, integration, and coordination) harming the development of the collaborative governance model.

The governance system integrates the opinion of experts who are often called upon to solve specific issues. Also, although to a lesser degree, it creates structured information in the formulation of policies (missing links), and it is uncommon to make use of more robust methods such as cost-benefit analysis. Participation in the creation of policies by the interviewed entities divides the perceptions. Half had classified it as strong or positive, and the other half said it did not exist. The less active participation is that of the citizens. However, the respondents' perception is that there are no conditions (health literacy and understanding of health as a collective capital) for its development.

The multilevel and multisectoral collaboration levels in the sRBV governance system are assessed positively, both when considering collaboration between national and regional decision-makers and when observing collaboration between decision-makers and those implementing policies. A distinction is made between entities with the mission of coordinating regional 
Table 3. Vertical and horizontal collaborative insensitivity (decision-makers, practitioners, and sectors)

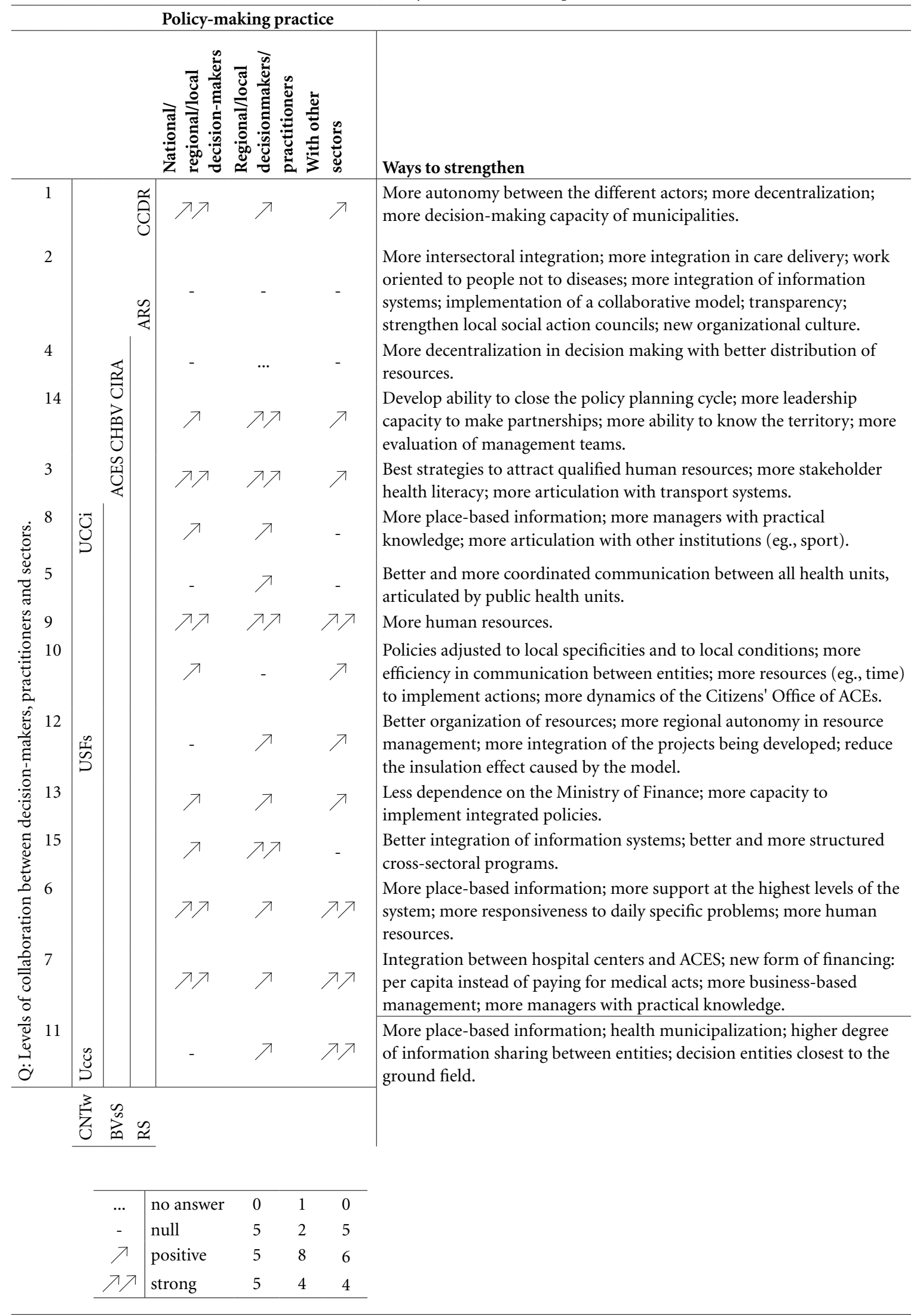

Source: Own elaboration. 
than the latter. Intersectoral collaboration is as frequent as close to the communities the services are provided. It is mainly the Community Care Units that develop projects jointly with other state entities (education, municipalities, and sports). This type of collaboration would be reinforced if the information and knowledge managed and developed by the stakeholders who provide care for (and together with) the communities were better integrated. Another possible contribution could be made by further developing autonomy mechanisms.

The governance system analyzed through the interviewed leaders' informed perception shows, partially, the dimensions identified in Chart 1. It shares part of the principles, processes, and outcomes systematized in the Collaborative Place-based Governance Framework (Figure 1). It is structured with a network of interactions between diverse stakeholders at multi-scale level sharing principles ${ }^{12}$, seeking to reduce inequities $^{1}$ through collective processes of making decisions that produce consensus ${ }^{1}$. However, it shows constraints in basing its decisions on local-based information, as Prehoda et al. ${ }^{12}$ argue. Nor does it show satisfactory levels of state/private stakeholders' arrangements assumed as an assumption of a collaborative governance system by Plochg et al. ${ }^{1}$.

The multisectoral collaboration levels provided for in Plochg et al. ${ }^{1}$ are still not desirable, found mainly in specific programs developed by caregivers close to the community. They do not have mechanisms that gather diverse people, organizations, and sectors that can change the way communities conceptualize and solve health problems. However, further developing the contractualized autonomy mechanisms, with assessment and accountability instruments implemented within primary care, aims to overcome part of the weaknesses identified in the governance system.

The results are not conclusive on how the respondents perceive the incorporation of guidelines in their institutions' workings. Most of them perceive that they are part of a hierarchical, bureaucratic, top-down organized system. However, for one in every three respondents, the perception is distinctive: they consider that they are part of a cooperative system, with a flexible hierarchy and the ability to adapt to tensions.

The inherent limitations in using interviews as a source of primary information preclude more extensive conclusions that would allow comparisons between the evaluations made by different types of entities. For example, it enables differentiating those providing health care and those coordinating policy formation, according to their scales of influence within the governance system.

However, the fieldwork process and the analysis of qualitative information allows us to realize that governance system's dimensions characterize a collaborative model and that there is still a lack of efforts to incorporate mechanisms to achieved a greater level of participation by interested citizens, greater proximity (more place-based) and more inter-sectoral collaboration. The strengthening of the collaborative and place-based governance system's dimensions can be achieved by incorporating planning instruments built from the bottom to the top, associated with mechanisms for contracting autonomy.

The research conducted allows us to better understand the perception of the stakeholders of a sub-regional governance system with responsibilities to create and implement health policies, analyzing their informed perceptions, assessing the intensity of the collaborative and placed-based dimensions. However, in later studies, quantitative dimensions will be added to improve the conclusions and, from them, present more specific policy guidelines. The relevance of a set of shared principles in the governance system, the mechanisms of multilevel and multisectoral collaboration, and actors' involvement (intra-system) in the formulation of policies from structured information should be highlighted in this study. According to interviewed leaders, it is urgent to strengthen the collaboration and integration of local needs in designing policies and the provision of healthcare.

\section{Collaborations}

C Gonçalves designed and coordinated the research work, structured and applied the fieldwork, structured and analyzed the information, and the text's writing. G Santinha supported the study's design, fieldwork, and the text's editing. A Santiago supported the organization of the information and the editing of the text. G Barros supported and applied the fieldwork, the organization of information, and the text's writing. 


\section{References}

1. Plochg T, Schmidt M, Klazinga N, Stronks K. Health governance by collaboration: A case study on an area-based programme to tackle health inequalities in the Dutch city of the Hague. Eur J Public Health 2013; 23(6):939-946.

2. Barbazza E, Tello JE. A review of health governance: Definitions, dimensions and tools to govern. Health Policy (New York) [serial on the Internet]. 2014 [acessado 2019 Mar 12]; 116(1):1-11. Available from: http:// dx.doi.org/10.1016/j.healthpol.2014.01.007

3. Santinha G. Governance for health: Is the cultural 'lone ranger' behaviour still prevailing? Perspectives from policymakers in Portugal. Public Policy Adm 2016; 31(2):147-168.

4. Bastos S, Reis M, Candoso F, Pisco AMSA, Monteiro BR. Cuidados primários em saúde em Portugal: 10 anos de contratualização com os serviços de saúde na Região de Lisboa. Cien Saude Colet 2017; 22(3):725-36

5. Abimbola S, Negin J, Jan S, Martiniuk A. Towards people-centred health systems: A multilevel framework for analysing primary health care governance in low-and middle-income countries. Health Policy Plan 2014; 29:ii29-39.

6. Lowe M, Whitzman C, Giles-Corti B. Health-Promoting Spatial Planning: Approaches for Strengthening Urban Policy Integration. Plan Theory Pract [serial on the Internet]. 2018 [acessado 2019 Mar 12]; 19(2):180197. Available from: http://doi.org/10.1080/14649357. 2017.1407820

7. Ansell C, Gash A. Collaborative governance in theory and practice. J Public Adm Res Theory 2008; 18(4):543571.

8. Lasker RD, Weiss ES, Miller R. Partnership Synergy: A Practical Framework for Studying and Strengthening the Collaborative Advantage. Milbank Q 2001; 79(2):179-205.

9. Balabanova D, Mills A, Conteh L, Akkazieva B, Banteyerga H, Dash U, Gilson L, Harmer A, Ibraimova A, Islam Z, Kidanu A, Koehlmoos TP, Limwattananon S, Muraleedharan VR, Murzalieva G, Palafox B, Panichkriangkrai W, Patcharanarumol W, Penn-Kekana L, Powell-Jackson T, Tangcharoensathien V, McKee M. Good health at low cost 25 years on: Lessons for the future of health systems strengthening. Lancet [serial on the Internet]. 2013 [acessado 2019 Mar 12]; 381(9883):2118-2133.
10. Baez-Camargo C, Jacobs E. A Framework to Assess Governance of Health Systems in Low Income Countries Basel Institute on Governance. Basileia: Basel Institute on Governance; 2011. (Working Paper Series, n.11)

11. Pyone T, Smith H, Van Den Broek N. Frameworks to assess health systems governance: A systematic review. Health Policy Plan 2017; 32(5):710-722.

12. Prehoda E, Winkler R, Schelly C. Putting Research to Action: Integrating Collaborative Governance and Community-Engaged Research for Community Solar. Soc Sci [periódico na Internet]. 2019 [acessado 2019 Mar 12]; 8(1):11. Disponível em: doi:10.3390/socsci8010011

13. Brinkerhoff DW, Bossert TJ. Health governance: Principal-agent linkages and health system strengthening. Health Policy Plan 2013; 29(6):685-693.

14. Pisco L, Pinto LF. From Alma-Ata to Astana : the path of Primary Health Care in Portugal, 1978-2018 and the genesis of Family Medicine. Cien Saude Colet 2020; 25(4):1197-1204.

15. Almeida Simoes J, Augusto GF, Fronteira I, HernandezQuevedo C. Portugal: Health System Review. Health Syst Transit 2017; 19(2):1-184.

16. ARS Centro. Plano de Atividades [Internet]. Administração Regional de Saúde do Centro, IP. 2019. [cited 2019 Mar 12]. Available from: http://dx.doi.org/10.1016/j.tws.2012.02.007

Article submitted on 10/03/2020

Approved on 05/08/2020

Final version submitted on $07 / 08 / 2020$

Chief editors: Maria Cecília de Souza Minayo, Romeu Gomes, Antônio Augusto Moura da Silva 